\title{
Effect of Percutaneous Ventricular Assist Devices on Renal Function
}

\author{
Huijuan Mao ${ }^{a, b}$, e Anna Giuliani ${ }^{a-c}$ Lourdes Blanca-Martos ${ }^{a, b}, f$ \\ Jeong Chul Kim ${ }^{a, b}$ Akash Nayak ${ }^{b, d}$ Grazia Virzi ${ }^{a}$, Alessandra Brocca ${ }^{a, b}$ \\ Elisa Scalzotto ${ }^{a, b}$ Mauro Neri ${ }^{a, b}$ Nevin Katz ${ }^{g}$ Claudio Ronco ${ }^{a, b}$
}

${ }^{a}$ Department of Nephrology, Dialysis and Transplantation, San Bortolo Hospital, and ${ }^{\mathrm{b}}$ International Renal Research Institute Vicenza, Vicenza, and ' Department of Clinical and Molecular Medicine, Sapienza University, Rome, Italy; ${ }^{\mathrm{d}}$ Department of Chemical Engineering and Economics BITS Pilani, Pilani, India; ${ }^{\circ}$ Department of Nephrology, First Affiliated Hospital of Nanjing Medical University, Nanjing, China; ${ }^{f}$ Department of Nephrology, Hospital Universitario Carlos Haya, Málaga, Spain; ${ }^{9}$ Department of Surgery, Johns Hopkins University, Baltimore, Md., USA

\section{Key Words}

Acute kidney injury $\cdot$ Cardiovascular disease $\cdot$ Kidney function test $\cdot$ Ventricular assist devices

\begin{abstract}
Ventricular assist devices (VADs) are used to improve the systemic circulation and to decrease ventricular loading in patients with hemodynamic instability that is refractory to pharmacologic therapies. During an acute critical event, percutaneous devices are preferred because of their rapid deployment, since implantable devices require more extensive procedures. Implantable devices are used for patients with established end-stage heart failure as a bridge to heart transplantation, recovery or destination therapy. This report reviews mechanical principles and clinical studies regarding percutaneous VAD to address their potential renal effects. Since the focus of this study is set on devices that are dedicated to cardiac support only, extracorporeal membrane oxygenation systems are not included.
\end{abstract}

Copyright $\odot 2013$ S. Karger AG, Basel

\begin{tabular}{|c|c|}
\hline KARGER & $\begin{array}{l}\text { (c) } 2013 \text { S. Karger AG, Basel } \\
0253-5068 / 13 / 0353-0119 \$ 38.00 / 0\end{array}$ \\
\hline $\begin{array}{l}\text { Fax +41 } 613061234 \\
\text { E-Mail karger@karger.com } \\
\text { www.karger.com }\end{array}$ & $\begin{array}{l}\text { Accessible online at: } \\
\text { www.karger.com/bpu }\end{array}$ \\
\hline
\end{tabular}

\section{Introduction}

Cardiovascular diseases (CVD) are the major cause of death worldwide [1]. In the USA, the 2007 overall death rate from CVD was 251.12 per 100,000 individuals [2]. Various therapeutic strategies for CVD are available, from lifestyle changes and medication to mechanical circulatory support. A ventricular assist device (VAD) can be used to improve the systemic circulation and to decrease the load on the myocardium prone to heart failure refractory to pharmacologic therapy. Depending on the method of VAD placement, a VAD can be categorized as a percutaneous device or as an implantable device. During an acute critical event, percutaneous devices are preferred due their rapid deployment since implantable devices require more extensive procedures. Implantable devices, however, are used for end-stage heart failure patients as a bridge to heart transplantation, recovery or destination therapy $[3,4]$.

Placement of a VAD has the potential to improve internal organ function by preventing or reversing organ hypoperfusion and allowing organ recovery [5]. Potentially, the use of a VAD could be associated with acute

Claudio Ronco, MD

Department of Nephrology, Dialysis and Transplantation, San Bortolo Hospital Viale Rodolfi 37

IT-36100 Vicenza (Italy)

E-Mail cronco@goldnet.it 
organ failure [6]. Interaction mechanisms between VAD and internal organs have been hypothesized [7-10].

Renal function prior to VAD placement is a predictor of clinical outcome. Optimal benefit from a VAD depends on balancing the interaction mechanisms between the VAD and the kidney during the pre-, intra- and postoperative periods. In their review of renal failure in patients treated with a left VAD (LVAD), Patel et al. [11] noted that significant number of patients with end-stage heart failure refractory to conventional medical therapy had renal dysfunction prior to LVAD implantation. The risk of acute kidney injury after LVAD implantation is reported to be $7-56 \%$. On the other hand, renal function may be improved after LVAD implantation, as measured by serum creatinine, creatinine clearance and estimated glomerular filtration rate (GFR). To assist in clinical decision-making, we reviewed mechanical principles and clinical studies of percutaneous heart-assist devices (intra-aortic balloon pump (IABP) Impella, TandemHeart and Cardiobridge) to address the potential renal effects of these devices. Because the focus of this study is set on the renal effects of devices dedicated to cardiac support only, extracorporeal membrane oxygenation systems are not included.

\section{Clinical Indications}

Although cardiac transplantation offers the best possible solution for patients with severe heart failure, many patients succumb to their disease while waiting for a transplant due to the high number of patients on the waiting list and the low number of transplants available. Therefore, the use of VADs, especially percutaneous VADs, has increased, since they have the advantages of rapid deployment and widespread availability.

In the following, the major indications for VADs are listed.

Cardiogenic Shock. Mortality from cardiogenic shock (CS) complicating acute myocardial infarction (AMI) is as high as $60-70 \%$ [12]. VAD use can result in significantly increased cardiac output (CO) and consequently end-organ perfusion. In turn, this diminishes the systemic inflammatory response syndrome that can add to the cardiac dysfunction. Delayed treatment of CS can lead to multiorgan failure. Some studies have reported that percutaneous VAD (pVAD) treatment improved CO by $37-43 \%[13,14]$. Differences in survival are key determinants in the design and analysis of VAD studies.
Bridging. Patients who are placed on a waiting list for a donor heart may require either temporary [15] or longterm VAD placement as a bridge to transplantation or to recovery per se. In the meantime, complications related to coronary artery disease, such as the postcardiotomy syndrome and myocarditis, can be addressed.

High-Risk Percutaneous Coronary and Valvular Interventions. Patients with severe left main coronary stenosis, either due to hemodynamic instability or comorbidities, have been shown to be at increased risk during percutaneous coronary interventions (PCI). The benefits of percutaneous ventricular support have been documented in a retrospective study of 144 patients by the Europella Registry [16] and in PROTECT II, a randomized controlled study including 305 patients [17].

Ventricular Tachycardia Ablation. The major advantage of a pVAD in this setting is the maintenance of hemodynamic stability during and early after the procedure. Without such a device, hemodynamic instability may preclude performance of an ablation procedure [18].

There is limited experience with regard to the use of pVADs in patients with right ventricular failure. However, successful treatment with a percutaneous right VAD (TandemHeart) has been described $[19,20]$. Overall, the major indications for pVADs are the need to treat CS when medical treatment combined with IABP is not sufficient, and the need to create stability during high-risk procedures. pVADs have the potential to provide stability while the patient is awaiting surgical long-term support or transplantation, especially in patients with profound hypotension and a high risk of mortality.

\section{Percutaneous Devices and Renal Function}

Several pVADs are available for mechanical circulatory support in the catheterization laboratory. The most widely used devices are the IABP, the TandemHeart system and the Impella 2.5. A number of novel pVADs have recently been developed, such as the Cardiobridge (Reitan catheter pump (RCP)). A comparison of the pVADs available is listed in table 1.

\section{Intra-Aortic Balloon Pump}

The IABP has been the most widely used pVAD since its introduction in 1968 [21] and is frequently the first assist device used in CS treatment. In the community setting, an IABP is generally inserted percutaneously via the femoral artery. The balloon is then positioned in the descending aorta, just distal to the left subclavian 
Table 1. Comparison of PVADs currently available

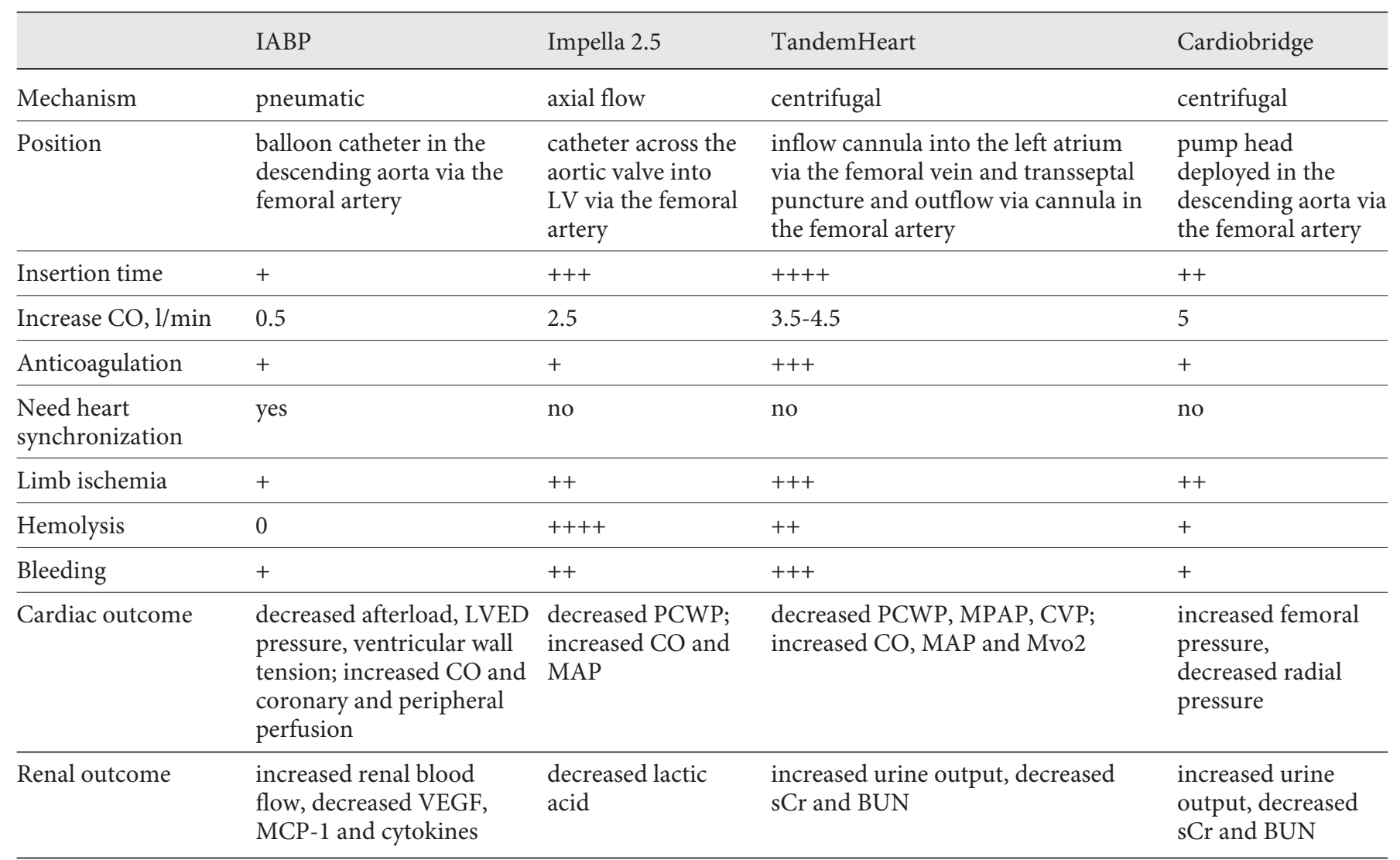

BUN = Blood urea nitrogen; CVP = central venous pressure; LVED = LV end-diastolic pressure; MAP = mean arterial pressure; MCP-1 = monocyte chemotactic protein-1; MPAP = mean pulmonary arterial pressure; Mvo2 = mixed venous oxygen saturation; $\mathrm{PCWP}=$ pulmonary capillary wedge pressure; $\mathrm{sCr}=$ serum creatinine; $\mathrm{VEGF}=$ vascular endothelial growth factor.

artery and well proximal to the renal arteries (fig. 1a). When balloon inflation occurs at the start of diastole and deflation before systole, the IABP can augment $\mathrm{CO}$ by $0.3-0.5 \mathrm{ml} / \mathrm{min}$ [22] depending on a stable native cardiac rhythm, the balloon volume, the aortic compliance and systemic vascular resistance. Studies have demonstrated its effect on CO and significant improvement in systemic perfusion due to increased diastolic pressure, decreased left ventricle (LV) end-diastolic pressure and decreased oxygen demand induced by the decrease in afterload and ventricular wall tension [23]. However, an IABP may not provide adequate circulatory support for patients with severe CS or hemodynamic instability due to severe cardiac arrhythmias. Thiele et al. [24] have addressed IABP use in patients with myocardial infarction with CS. The use of an IABP for CS after ST-segment elevation myocardial infarc- tion has a class I guideline recommendation [25]. The reported morbidity rate related to IABP insertion is 8.7$29 \%[26,27]$, but there is no significant association between IABP-related complications and short- or longterm mortality $[28,29]$.

Renal dysfunction associated with cardiac surgery influences short- and long-term mortality [30, 31]. Factors such as perioperative hypotension, use of potential nephrotoxic therapeutic agents, radiopaque contrast media, cardiopulmonary bypass and IABP have been identified as factors contributing to renal dysfunction associated with cardiac surgery [32]. In a multivariate model, the preoperative patient characteristic most strongly associated with postoperative severe renal insufficiency (estimated GFR $<30 \mathrm{ml} / \mathrm{min} / 1.73 \mathrm{~m}^{2}$ ) was preoperative IABP use [30,33]. Interpretation is difficult, as use of an IABP usually indicates a severe clinical state. Clinicians 


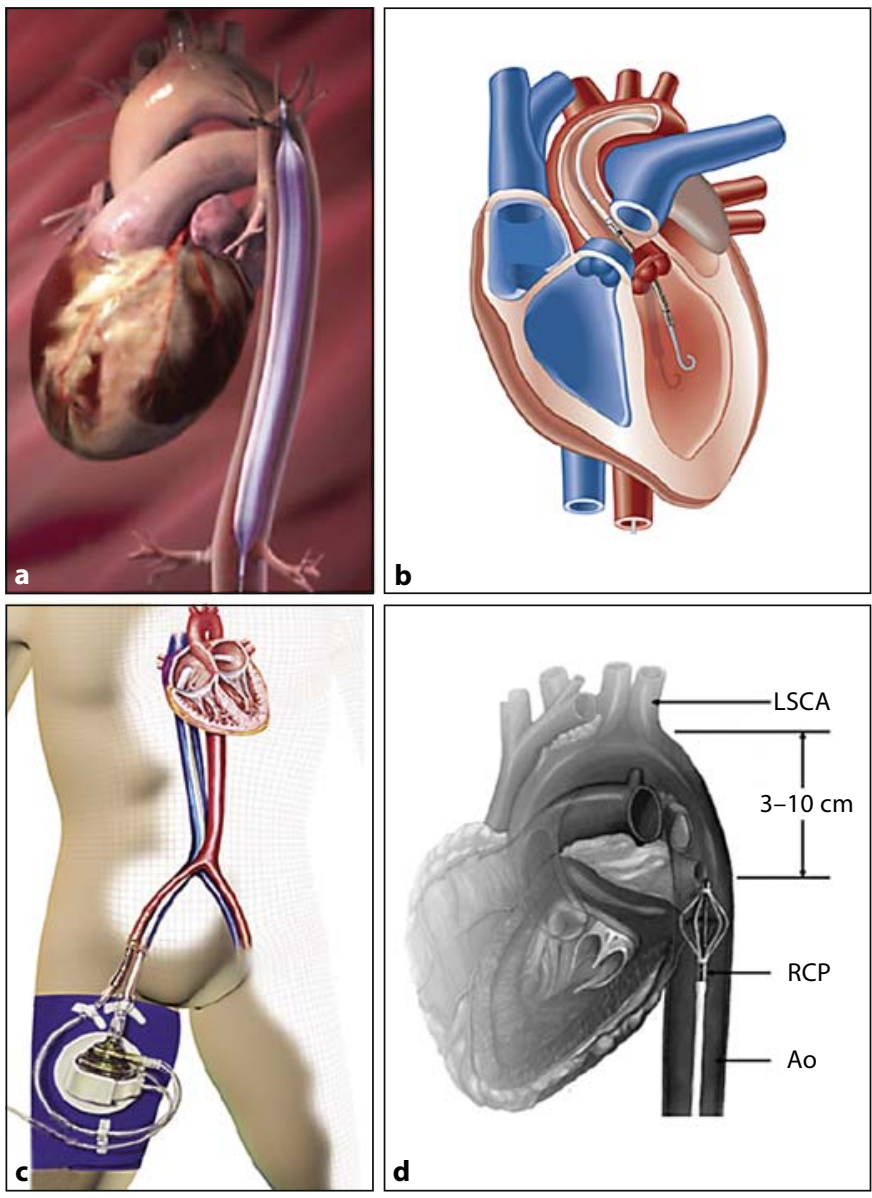

Fig. 1. a IABP: it is inserted in the femoral artery and the balloon is positioned in the descending aorta distal to the left subclavian artery and proximal to the renal artery branches. b Impella 2.5: it is positioned across the aortic valve in the $\mathrm{LV}$, aspirates blood from the LV and pumps it into the ascending aorta. c TandemHeart: it aspirates oxygenated blood from the left atrium via a transeptal cannula placed in the femoral vein and returns blood via the femoral artery to the lower abdominal aorta. $\mathbf{d}$ Cardiobridge: it is positioned in the descending aorta and creates a pressure gradient.

are faced with the question whether the use of an IABP is safe for patients with renal failure.

The effect of the IABP on renal blood flow in high-risk patients was studied by Sloth et al. [1]. They found that renal artery diameters were unchanged, and that there was no decrease in renal resistance and/or compliance. Interlobar renal blood flow was higher during IABP treatment measured by Doppler ultrasound, without a simultaneous change in creatinine clearance. In a study of the use of an IABP during cardioplegic arrest, Onorati et al. [34] found that IABP use induced hemodynamic improvement which resulted in lower serum IL-2 and IL-6 and higher IL-10 levels, lower endothelial markers (vascular endothelial growth factor and monocyte chemotactic protein-1) [35] together with improved estimated GFR, lower creatinine from admission to the intensive care unit to $48 \mathrm{~h}$ in patients with preoperative kidney disease of stages $1-2$ and 3 . The incidence of renal insufficiency and the need for renal replacement therapy were also lower in stage 3 IABP. IABPinduced pulsatile flow was also found to improve whole body perfusion including renal function in the elderly undergoing cardiopulmonary bypass surgery [36].

Muniraju et al. [37] reported a prospective observational study of the use of a preoperative IABP in patients undergoing elective off-pump coronary artery bypass surgery. They found no change in serum creatinine from the baseline value of $1.10 \pm 0.233$ to $0.98 \pm 0.363 \mathrm{mg} / \mathrm{dl}(\mathrm{p}>$ 0.05). Cystatin $C$ levels were significantly decreased from the baseline level of $0.98 \pm 0.29$ to $0.89 \pm 0.23(\mathrm{p}<0.05)$. Lack of an elevation in cystatin $C$ levels also suggested absence of potentially IABP-induced renal dysfunction in patients on elective IABP therapy preoperatively. Recently, in a randomized, prospective, open-label, multicenter trial including 600 patients, IABP use did not significantly reduce 30-day mortality and resulted in no difference in renal function in patients with CS complicating AMI for whom an early revascularization strategy was planned [24].

\section{Impella}

The Impella ${ }^{\circledR}$ Recover ${ }^{\circledR}$ LP Support System (AbioMed) is a continuous-flow, microaxial blood pump designed for rapid institution of temporary circulatory support. Two models are available, Impella 2.5 and Impella 5.0. The former can provide up to $2.5 \mathrm{l} / \mathrm{min}$ and can be percutaneously inserted, whereas the latter can deliver up to $5.0 \mathrm{l} / \mathrm{min}$, but requires a surgical incision for insertion into a peripheral artery or directly into the ascending aorta. The Impella is positioned across the aortic valve in the LV. The Impella pump aspirates blood from the LV and pumps it into the ascending aorta (fig. 1b). The amount of flow depends on the rotation speed (max. $32,000 \mathrm{rpm}$ ) and on the pressure gradient between the aorta and the LV. The Impella 2.5 is FDA approved for up to $6 \mathrm{~h}$ of partial circulatory support. The Impella directly unloads the LV which results in increased $\mathrm{CO}$ and mean arterial pressure and decreased pulmonary capillary wedge pressure and lactic acid levels $[14,38]$. Several studies have shown that Impella is effective and safe in STsegment elevation myocardial infarction and high-risk PCI patients $[39,40]$; however, experience in CS patients 
is limited [14], and there are no data that demonstrate a reduction in mortality rates [41].

From a physiologic point of view, kidney function should improve after pVAD implantation if the baseline renal dysfunction is secondary to low $\mathrm{CO}$, poor renal perfusion or renal venous congestion. However, there is no study investigating renal function changes after Impella implantation in a large patient cohort. In a case report which included 3 patients who underwent high-risk coronary angioplasty, use of the Impella 2.5 system resulted in an increase in serum creatinine of $1 \mathrm{mg} / \mathrm{dl}$ (from 1.8 to 2.8 $\mathrm{mg} / \mathrm{dl})$. The author analyzed the renal dysfunction due to contrast medium (mean amount of $323 \mathrm{ml}$ ) [42]. In another study, the Impella 2.5 was implanted in patients with CS $(n=6)$ or in patients undergoing high-risk PCI $(n=5)$. Renal failure was observed in 4 patients, all of whom had CS [43]. Considering the complicated clinical condition and limited sample size, it could not be concluded that the use of the Impella 2.5 has a potential adverse effect on renal function. In another study, use of the Impella 5.0 in 5 patients with CS and severe renal failure with oliguria or anuria was associated with hemodynamic improvement, and a decrease in mean serum creatinine level from 176.8 to $79.6 \mu \mathrm{mol} / \mathrm{l} 15$ days after implantation $(\mathrm{p}=0.02)$ [44].

Use of the Impella has been associated with increased levels of hemolysis and its secondary effects. A higher incidence of hemolysis has been reported in patients treated with an Impella versus an IABP [41]. Acute kidney injury secondary to severe hemolysis after Impella 2.5 placement has been reported [45]. In patients who develop hemolytic anemia after Impella insertion, urinary output and renal function should be closely monitored. Cannula position should be evaluated, and the flow reduced as tolerated. The device should be removed as early as possible to reduce the extent of hemolysis and preserve renal function.

\section{TandemHeart}

The TandemHeart is a continuous-flow, extracorporeal pump that can provide temporary support from a few hours up to 14 days, to facilitate cardiac recovery. The TandemHeart aspirates oxygenated blood from the left atrium via a transseptal cannula that has been placed in the femoral vein. The pump returns blood to the femoral artery or lower abdominal aorta establishing a left-atrialto-femoral arterial bypass (fig. 1c). The pump has an internal system of continuous heparin administration via the device lubrication system to reduce the need for systemic anticoagulation. At the maximum rotational speed of 7,500 rpm, the TandemHeart can deliver blood flow up $4-5 \mathrm{l} / \mathrm{min}$. The system is used in CS complicated by AMI and in high-risk PCI. Studies have demonstrated that the TandemHeart can increase the cardiac index, blood pressure, mixed venous oxygen saturation, urine output and reverse hemodynamic instability with subsequent decreases in pulmonary capillary wedge pressure, mean pulmonary arterial pressure and central venous pressure $[13,46]$. The major risks of the TandemHeart are bleeding and limb ischemia.

There are few studies investigating changes in renal function after TandemHeart support. The TandemHeart has been compared with IABP support in 41 patients with revascularized AMI complicated by CS [13]. The cardiac power index was more effectively improved by the TandemHeart and was accompanied by a more rapid decrease in serum lactate and improved renal function. However, there were no significant differences with respect to 30-day mortality, and complications, including limb ischemia and severe bleeding, were more frequent with the TandemHeart than with IABP support.

With regard to renal function, in a study of TandemHeart implantation during high-risk PCI, Aragon et al. [47] reported that 1 of 8 patients developed acute renal failure after the procedure and required hemodialysis. Gregoric et al. [48] studied 8 patients with cardiac arrest or severe refractory CS receiving TandemHeart support for $6.4 \pm 3.8$ days before aortic valve replacement for critical aortic valve stenosis in the catheterization laboratory and noted significant improvement in renal function with decreases in serum creatinine $(2.0 \pm 0.9$ to $1.1 \pm 0.3 \mathrm{mg} /$ $\mathrm{dl} ; \mathrm{p}=0.002)$ and blood urea nitrogen ( $46.5 \pm 26.5$ to 28.9 $\pm 13.3 \mathrm{mg} / \mathrm{dl} ; \mathrm{p}=0.023$ ). Before $\mathrm{pVAD}$ placement, 6 of the 8 patients were anuric, whereas during TandemHeart support, urine output improved and reached $155 \pm 78 \mathrm{ml} / \mathrm{h}$. While improvement in hemodynamic parameters by the TandemHeart appears promising, it remains to be determined whether this benefit translates into reversed organ dysfunction and improved clinical outcomes.

\section{Cardiobridge (RCP)}

The Cardiobridge support device (RCP) is a continuous nonphasic pump that consists of a catheter-mounted pump head with a foldable propeller and surrounding cage (fig. 1d). Its unique foldable propeller mechanism allows for percutaneous insertion. Positioned in the descending aorta, the pump creates a pressure gradient, reduces afterload and enhances organ perfusion. The pump functions without the need for heart synchronization and is not limited by the state of the aortic valve (native or prosthetic). The RCP is not positioned within the LV cavity and therefore is not contraindicated in the presence of LV thrombus. 
Smith et al. [49] reported a first-in-man study of the RCP implanted in 10 consecutive patients requiring circulatory support who underwent PCI. RCP was inserted via the femoral artery before PCI and was removed $1-6 \mathrm{~h}$ after the procedure. The pump operated successfully in 9 of 10 cases (median $79 \mathrm{~min}$ ). There was no significant hemolysis, and platelet counts were unchanged. Baseline serum creatinine (before RCP) fell during a mean of $14 \mathrm{~h}$ in 7 of 9 patients after pump removal, with a mean reduction of $11 \pm 8 \mu \mathrm{mol} / \mathrm{l}(\mathrm{p}=0.004)$ and a corresponding increase in GFR from $66.7 \pm 18.1$ to $74.9 \pm 23.6 \mathrm{ml} / \mathrm{min}$.

In an unpublished study (author communication) of the hemodynamic efficacy of RCP in patients with acute decompensated chronic heart failure, the RCP brought about a rapid and marked diuresis.

Urine output increased from a baseline of $54 \mathrm{ml} / \mathrm{min}$ to $213 \mathrm{ml} / \mathrm{h}$ after $12 \mathrm{~h}(\mathrm{p}=0.029)$. Serum creatinine fell from 193 to $151 \mu \mathrm{mol} / \mathrm{l}$ at $12 \mathrm{~h}(\mathrm{p}=0.003,22 \%$ reduction). Further study of this device which has promising early results is needed.

\section{Chronic Renal Disease}

In the acute-care setting, for example CS treatment, it is not possible to distinguish renal dysfunction that occurs as a result of acute hypoperfusion from renal dysfunction related to preexisting chronic kidney disease. Consequently, delay in restoring organ perfusion or addressing a nephrotoxic event, such as contrast medium exposure or hemolysis, can slow recovery of renal function or lead to irreversible damage and the associated worse outcomes. It is of note that nearly two thirds of hospitalized patients with heart failure also have chronic kidney disease and are less likely to receive important guideline-recommended therapies [50].

\section{Conclusion}

The major indications for pVADs are hemodynamic instability due to acute heart disease, the threat of hemodynamic instability during high-risk PCI and valvular interventions, and the need for a temporary bridge to heart transplantation or an implantable VAD. An important consequence of hemodynamic instability and CS is end-organ hypofusion with resulting injury. Low urine output, a marker of kidney hypoperfusion, is one of the criteria used to define CS and is well known to be associated with worse outcomes. pVAD insertion with hemodynamic improvement should improve kidney function as a result of the restoration of perfusion. However, there are only a few studies reporting the effect of pVADs on kidney function, and the patient numbers studied are small. Nevertheless, the available clinical data support pVAD as a means to reverse and prevent renal failure in patients with marked hemodynamic compromise. In that kidney function is one of the most reliable predictors of outcome in the setting of acute heart disease, the pVAD should be chosen depending on its expected renal effects.

\section{Acknowledgment}

The study was supported in part by a research grant from the JiangSu Government Scholarship for overseas studies, China (JS2010-127), the Medical Scientific Research Foundation of the Jiangsu Province, China (Z201002), the Italian Society of Nephrology, the Spanish Society of Nephrology and the International Renal Research Institute of Vicenza.

\section{Disclosure Statement}

All of the authors declare no competing interests.
References
Sloth E, Sprogoe P, Lindskov C, Horlyck A, Solvig J, Jakobsen C: Intra-aortic balloon pumping increases renal blood flow in patients with low left ventricular ejection fraction. Perfusion 2008;23:223-226.

-2 Roger VL, Go AS, Lloyd-Jones DM, Adams RJ, Berry JD, Brown TM, Carnethon MR, Dai S, de Simone G, Ford ES, Fox CS, Fullerton HJ, Gillespie C, Greenlund KJ, Hailpern SM, Heit JA, Ho PM, Howard VJ, Kissela BM, Kittner SJ, Lackland DT, Lichtman JH, Lisabeth LD, Makuc DM, Marcus GM, Marelli A, Matchar DB, McDermott MM, Meigs JB,
Moy CS, Mozaffarian D, Mussolino ME, Nichol G, Paynter NP, Rosamond WD, Sorlie PD, Stafford RS, Turan TN, Turner MB, Wong ND, Wylie-Rosett J: Heart disease and stroke statistics - 2011 update: a report from the American Heart Association. Circulation 2011;123:e18-e209.

- 3 Park SJ, Tector A, Piccioni W, Raines E, Gelijns A, Moskowitz A, Rose E, Holman W, Furukawa S, Frazier OH, Dembitsky W: Left ventricular assist devices as destination therapy: a new look at survival. J Thorac Cardiovasc Surg 2005;129:9-17. 
-4 Lietz K, Long JW, Kfoury AG, Slaughter MS, Silver MA, Milano CA, Rogers JG, Naka Y, Mancini D, Miller LW: Outcomes of left ventricular assist device implantation as destination therapy in the post-REMATCH era: implications for patient selection. Circulation 2007;116:497-505.

5 Burnett CM, Duncan JM, Frazier OH, Sweeney MS, Vega JD, Radovancevic B: Improved multiorgan function after prolonged univentricular support. Ann Thorac Surg 1993; 55:65-71, discussion 71.

-6 Frazier OH, Rose EA, Oz MC, Dembitsky W, McCarthy P, Radovancevic B, Poirier VL, Dasse KA: Multicenter clinical evaluation of the HeartMate vented electric left ventricular assist system in patients awaiting heart transplantation. J Thorac Cardiovasc Surg 2001;122:1186-1195.

7 Farrar DJ, Hill JD: Recovery of major organ function in patients awaiting heart transplantation with Thoratec ventricular assist devices. Thoratec Ventricular Assist Device Principal Investigators. J Heart Lung Transplant 1994;13:1125-1132.

8 Zimpfer D, Wieselthaler G, Czerny M, Fakin R, Haider D, Zrunek P, Roethy W, Schima H, Wolner E, Grimm M: Neurocognitive function in patients with ventricular assist devices: a comparison of pulsatile and continuous blood flow devices. ASAIO J 2006;52:24-27.

-9 James KB, McCarthy PM, Jaalouk S, Bravo EL, Betkowski A, Thomas JD, Nakatani S, Fouad-Tarazi FM: Plasma volume and its regulatory factors in congestive heart failure after implantation of long-term left ventricular assist devices. Circulation 1996;93: 1515-1519.

-10 James KB, McCarthy PM, Thomas JD, Vargo R, Hobbs RE, Sapp S, Bravo E: Effect of the implantable left ventricular assist device on neuroendocrine activation in heart failure. Circulation 1995;92:II191-195.

11 Patel AM, Adeseun GA, Ahmed I, Mitter N, Rame JE, Rudnick MR: Renal failure in patients with left ventricular assist devices. Clin J Am Soc Nephrol 2012, E-pub ahead of print.

-12 Barron HV, Every NR, Parsons LS, Angeja B, Goldberg RJ, Gore JM, Chou TM: The use of intra-aortic balloon counterpulsation in patients with cardiogenic shock complicating acute myocardial infarction: data from the National Registry of Myocardial Infarction 2. Am Heart J 2001;141:933-939.

-13 Thiele H, Sick P, Boudriot E, Diederich KW, Hambrecht R, Niebauer J, Schuler G: Randomized comparison of intra-aortic balloon support with a percutaneous left ventricular assist device in patients with revascularized acute myocardial infarction complicated by cardiogenic shock. Eur Heart J 2005;26: $1276-1283$.
14 Meyns B, Dens J, Sergeant P, Herijgers P, Daenen W, Flameng W: Initial experiences with the Impella device in patients with cardiogenic shock - Impella support for cardiogenic shock. Thorac Cardiovasc Surg 2003; 51:312-317.

15 Badawi RA, Grise MA, Thornton SN: Impella 2.5 assisted balloon aortic valvuloplasty and percutaneous coronary intervention as a bridge to heart transplantation. J Invasive Cardiol 2012;24:229-230.

- 16 Sjauw KD, Konorza T, Erbel R, Danna PL, Viecca M, Minden HH, Butter C, Engstrom T, Hassager C, Machado FP, Pedrazzini G, Wagner DR, Schamberger R, Kerber S, Mathey DG, Schofer J, Engstrom AE, Henriques JP: Supported high-risk percutaneous coronary intervention with the Impella 2.5 device the Europella registry. J Am Coll Cardiol 2009;54:2430-2434.

17 O'Neill WW, Kleiman NS, Moses J, Henriques JP, Dixon S, Massaro J, Palacios I, Maini B, Mulukutla S, Dzavik V, Popma J, Douglas PS, Ohman M: A prospective, randomized clinical trial of hemodynamic support with Impella 2.5 versus intra-aortic balloon pump in patients undergoing high-risk percutaneous coronary intervention: the PROTECT II study. Circulation 2012;126: 1717-1727.

18 Bunch TJ, Mahapatra S, Madhu Reddy Y, Lakkireddy D: The role of percutaneous left ventricular assist devices during ventricular tachycardia ablation. Europace 2012;14 (suppl 2):ii26-ii32.

19 Giesler GM, Gomez JS, Letsou G, Vooletich M, Smalling RW: Initial report of percutaneous right ventricular assist for right ventricular shock secondary to right ventricular infarction. Catheter Cardiovasc Interv 2006; 68:263-266.

20 Atiemo AD, Conte JV, Heldman AW: Resuscitation and recovery from acute right ventricular failure using a percutaneous right ventricular assist device. Catheter Cardiovasc Interv 2006;68:78-82.

21 Kantrowitz A, Tjonneland S, Freed PS, Phillips SJ, Butner AN, Sherman JL Jr: Initial clinical experience with intraaortic balloon pumping in cardiogenic shock. JAMA 1968; 203:113-118.

-22 Watson JT, Willerson JT, Fixler DE, Browning RM, Sugg WL: Changes in collateral coronary blood flow (CCBF) distal to a coronary occlusion during intra-aortic balloon pumping (IABP). Trans Am Soc Artif Intern Organs 1973;19:402-407.

23 Ouweneel DM, Henriques JP: Percutaneous cardiac support devices for cardiogenic shock: current indications and recommendations. Heart 2012;98:1246-1254.
24 Thiele H, Zeymer U, Neumann FJ, Ferenc M, Olbrich HG, Hausleiter J, Richardt G, Hennersdorf M, Empen K, Fuernau G, Desch S, Eitel I, Hambrecht R, Fuhrmann J, Bohm M, Ebelt H, Schneider S, Schuler G, Werdan $\mathrm{K}, \mathrm{IABP}-\mathrm{SHOCK}$ II Trial Investigators I-SIT: Intraaortic balloon support for myocardial infarction with cardiogenic shock. N Engl J Med 2012;367:1287-1296.

25 Engstrom AE, Piek JJ, Henriques JP: Percutaneous left ventricular assist devices for high-risk percutaneous coronary intervention. Expert Rev Cardiovasc Ther 2010;8: 1247-1255.

26 Di Lello F, Mullen DC, Flemma RJ, Anderson AJ, Kleinman LH, Werner PH: Results of intraaortic balloon pumping after cardiac surgery: experience with the Percor balloon catheter. Ann Thorac Surg 1988;46:442446.

27 Mackenzie DJ, Wagner WH, Kulber DA, Treiman RL, Cossman DV, Foran RF, Cohen JL, Levin PM: Vascular complications of the intra-aortic balloon pump. Am J Surg 1992; 164:517-521.

28 Arafa OE, Geiran OR, Andersen K, Fosse E, Simonsen S, Svennevig JL: Intraaortic balloon pumping for predominantly right ventricular failure after heart transplantation. Ann Thorac Surg 2000;70:1587-1593.

29 Naunheim KS, Swartz MT, Pennington DG, Fiore AC, McBride LR, Peigh PS, Barnett MG, Vaca KJ, Kaiser GC, Willman VL: Intraaortic balloon pumping in patients requiring cardiac operations. Risk analysis and long-term follow-up. J Thorac Cardiovasc Surg 1992;104:1654-1660, discussion 1660-1661.

30 Brown JR, Cochran RP, Leavitt BJ, Dacey LJ, Ross CS, MacKenzie TA, Kunzelman KS, Kramer RS, Hernandez F Jr, Helm RE, Westbrook BM, Dunton RF, Malenka DJ, O'Connor GT, Northern New England Cardiovascular Disease Study Group: Multivariable prediction of renal insufficiency developing after cardiac surgery. Circulation 2007;116:1139-143

31 Jyrala A, Weiss RE, Jeffries RA, Kay GL: Effect of mild renal dysfunction (s-crea 1.2-2.2 $\mathrm{mg} / \mathrm{dl}$ ) on presentation characteristics and short- and long-term outcomes of on-pump cardiac surgery patients. Interact Cardiovasc Thorac Surg 2010;10:777-782.

32 Wang J, Xiao F, Li Y, Xin W, Yang Y, Li X, Song B, Zhu S: Risk factors for operative mortality in 1,098 patients with coronary artery bypass grafting surgery: a single center report (in Chinese). Beijing Da Xue Xue Bao 2011;43:134-139.

33 Thakar CV, Arrigain S, Worley S, Yared JP, Paganini EP: A clinical score to predict acute renal failure after cardiac surgery. J Am Soc Nephrol 2005;16:162-168. 
-34 Onorati F, Santarpino G, Rubino AS, Caroleo S, Dardano A, Scalas C, Gulletta E, Santangelo E, Renzulli A: Body perfusion during adult cardiopulmonary bypass is improved by pulsatile flow with intra-aortic balloon pump. Int J Artif Organs 2009;32:50-61.

- 35 Serraino GF, Marsico R, Musolino G, Ventura V, Gulletta E, Sante P, Renzulli A: Pulsatile cardiopulmonary bypass with intraaortic balloon pump improves organ function and reduces endothelial activation. Circ J 2012;76:1121-1129.

- 36 Onorati F, Santarpino G, Presta P, Caroleo S, Abdalla K, Santangelo E, Gulletta E, Fuiano G, Costanzo FS, Renzulli A: Pulsatile perfusion with intra-aortic balloon pumping ameliorates whole body response to cardiopulmonary bypass in the elderly. Crit Care Med 2009;37:902-911.

- 37 Muniraju G, Pandey S, Chakravarthy M, Krishnamoorthy J, Narayan S, Jawali V: Intra-aortic balloon pump use does not affect the renal function in patients undergoing off pump coronary artery bypass surgery. Ann Card Anaesth 2011;14:188-191.

- 38 Kar B, Basra SS, Shah NR, Loyalka P: Percutaneous circulatory support in cardiogenic shock: interventional bridge to recovery. Circulation 2012;125:1809-1817.

- 39 Henriques JP, Remmelink M, Baan J Jr, van der Schaaf RJ, Vis MM, Koch KT, Scholten EW, de Mol BA, Tijssen JG, Piek JJ, de Winter RJ: Safety and feasibility of elective high-risk percutaneous coronary intervention procedures with left ventricular support of the Impella Recover LP 2.5. Am J Cardiol 2006;97: 990-992.
40 Dixon SR, Henriques JP, Mauri L, Sjauw K, Civitello A, Kar B, Loyalka P, Resnic FS, Teirstein P, Makkar R, Palacios IF, Collins M, Moses J, Benali K, O’Neill WW: A prospective feasibility trial investigating the use of the Impella 2.5 system in patients undergoing high-risk percutaneous coronary intervention (the PROTECT I Trial): initial U.S. Experience. JACC Cardiovasc Interv 2009;2:91-96.

41 Seyfarth M, Sibbing D, Bauer I, Frohlich G, Bott-Flugel L, Byrne R, Dirschinger J, Kastrati A, Schomig A: A randomized clinical trial to evaluate the safety and efficacy of a percutaneous left ventricular assist device versus intra-aortic balloon pumping for treatment of cardiogenic shock caused by myocardial infarction. J Am Coll Cardiol 2008;52:1584-1588.

42 Thomopoulou S, Manginas A, Cokkinos DV: Initial experience with the Impella Recover LP 2.5 micro-axial pump in patients undergoing high-risk coronary angioplasty. Hellenic J Cardiol 2008;49:382-387.

43 Vecchio S, Chechi T, Giuliani G, Lilli A, Consoli L, Spaziani G, Giannotti F, Margheri M: Use of Impella Recover 2.5 left ventricular assist device in patients with cardiogenic shock or undergoing high-risk percutaneous coronary intervention procedures: experience of a high-volume center. Minerva Cardioangiol 2008;56:391-399.

44 La Torre MW, Centofanti P, Attisani M, Patane F, Rinaldi M: Posterior ventricular septal defect in presence of cardiogenic shock: early implantation of the Impella Recover LP 5.0 as a bridge to surgery. Tex Heart Inst J 2011;38:42-49.
45 Sibbald M, Dzavik V: Severe hemolysis associated with use of the Impella LP 2.5 mechanical assist device. Catheter Cardiovasc Interv 2012;80:840-844.

46 Thiele H, Lauer B, Hambrecht R, Boudriot E, Cohen HA, Schuler G: Reversal of cardiogenic shock by percutaneous left atrial-tofemoral arterial bypass assistance. Circulation 2001;104:2917-2922.

47 Aragon J, Lee MS, Kar S, Makkar RR: Percutaneous left ventricular assist device: 'TandemHeart' for high-risk coronary intervention. Catheter Cardiovasc Interv 2005;65: 346-352.

48 Gregoric ID, Loyalka P, Radovancevic R, Jovic $\mathrm{Z}$, Frazier OH, Kar B: TandemHeart as a rescue therapy for patients with critical aortic valve stenosis. Ann Thorac Surg 2009;88: 1822-1826.

49 Smith EJ, Reitan O, Keeble T, Dixon K, Rothman MT: A first-in-man study of the Reitan catheter pump for circulatory support in patients undergoing high-risk percutaneous coronary intervention. Catheter Cardiovasc Interv 2009;73:859-865.

50 Patel UD, Hernandez AF, Liang L, Peterson ED, LaBresh KA, Yancy CW, Albert NM, Ellrodt G, Fonarow GC: Quality of care and outcomes among patients with heart failure and chronic kidney disease: a Get with the Guidelines-Heart Failure Program Study. Am Heart J 2008;156:674-681. 